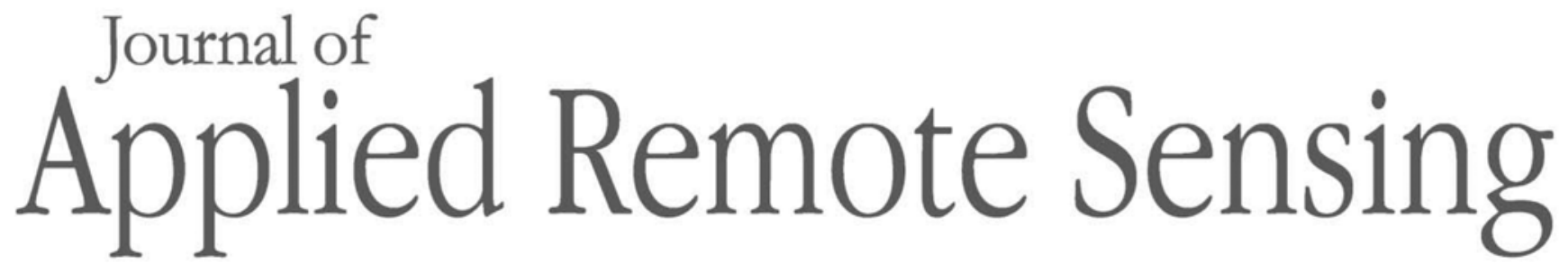

RemoteSensing.SPIEDigitalLibrary.org

\title{
Evaluation of camouflage effectiveness using hyperspectral images (Erratum)
}

Ahmad Zavvartorbati

Hamid Dehghani

Ali Jabar Rashidi 


\title{
Evaluation of camouflage effectiveness using hyperspectral images (Erratum)
}

\author{
Ahmad Zavvartorbati, Hamid Dehghani,* and Ali Jabar Rashidi \\ Malek Ashtar University of Technology, Department of Telecommunications Engineering, \\ Lavizan, Tehran, Iran
}

The corresponding author of this article [J. Appl. Remote Sens. 11(4), 045008 (2017)] has changed from Ahmad Zavvartorbati to Hamid Dehghani, as noted in the author list above. All online versions of the article were corrected on 19 February 2018.

*Address all correspondence to: Hamid Dehghani, E-mail: hamid_deh@yahoo.com

(C) 2018 Society of Photo-Optical Instrumentation Engineers (SPIE) 